\title{
Analisis Keberlanjutan Biogas Limbah Tahu Pedesaan (Studi Kasus Di Desa Kalisari, Kabupaten Banyumas)
}

\author{
Desty Ristianingsih ${ }^{1}$, Arya Hadi Dharmawan², Eka Intan Kumala Putri ${ }^{3}$ \\ 1 Program Studi Pengelolaan Sumberdaya Alam dan Lingkungan, Fakultas Pascasarjana, Institut Pertanian Bogor \\ 2Departemen Sains Komunikasi dan Pengembangan Masyarakat, Fakultas Ekologi Manusia, Institut Pertanian Bogor \\ ${ }_{3}^{3}$ Departemen Ekonomi dan Sumberdaya Lingkungan, Fakultas Ekonomi dan Manajemen, Institut Pertanian Bogor \\ *e-mail: destyristianingsih@yahoo.com; aryahadidharmawan2@gmail.com; ekaintanputri2@gmail.com
}

\begin{abstract}
ABSTRAK
Limbah cair tahu di Desa Kalisari diolah menjadi biogas untuk mencukupi kebutuhan energi rumahtangga. Faktorfaktor yang mempengaruhi kinerja biogas limbah tahu sangat menentukan keberlanjutan biogas limbah tahu. Penelitian ini bertujuan untuk mengetahui status keberlanjutan biogas limbah tahu dengan menggunakan pendekatan Multidimensional Scaling (MDS) berdasarkan lima dimensi yaitu sosial, ekonomi, ekologi, kelembagaan dan teknologi. Hasil analisis MDS menunjukkan bahwa dimensi sosial, ekonomi, ekologi dan kelembagaan berstatus cukup berkelanjutan. Dimensi teknologi berada pada status kurang berkelanjutan. Biogas limbah tahu dipandang efektif sebagai energi alternatif rumahtangga karena mengurangi beban kerja perempuan dan menjadi sarana resolusi konflik antara petani dan pengrajin tahu. Total manfaat ekonomi mencapai Rp 2058344 100/tahun namun secara ekonomi nilai tersebut belum efektif sebab biogas hanya dapat memenuhi sekitar 18\% rumahtangga dari keseluruhan rumahtangga di Desa Kaliasari.
\end{abstract}

Kata kunci: Biogas, MDS, energi pedesaan, keberlanjutan, limbah tahu

\begin{abstract}
Liquid tofu waste in Kalisari Village was processed into biogas to fulfill household energy needs. The factors that influence the performance of biogas from tofu waste determine the sustainability. This study was aimed to analysed the sustainability status of biogas from tofu waste using Multidimensional Scaling (MDS) approach based on five dimensions of social, economic, ecology, institutional and technology. The result showed that the social, economic, ecological and institutional dimensions were quite sustainable besides, the technology dimension was found in a less sustainable. Biogas from tofu waste was effective as an alternative energy for rural communities because reduced workload of women and as a conflict resolution between farmers and tofu craftsmen. The total economic benefit amounted Rp 2058344 100/year but it has not been effective because biogas only provide 18\% of household from whole communities in Kalisari Village.
\end{abstract}

Keywords: Biogas, MDS, rural energy, sustainability, tofu waste

Sitasi: Ristianingsih, D., Dharmawan, A.H. dan Putri, E.I.K (2018). Analisis Keberlanjutan Biogas Limbah Tahu Pedesaan (Studi Kasus Di Desa Kalisari, Kabupaten Banyumas). Jurnal Ilmu Lingkungan, 16(2), 104-112, doi:10.14710/jil.16.2.104-112

\section{Latar Belakang}

Energi fosil seperti minyak bumi, batu bara dan gas alam telah menjadi penggerak pertumbuhan ekonomi Indonesia. Penggunaan bahan bakar utama dari total permintaan energi Indonesia, minyak bumi mendominasi sebesar $42.3 \%$, batu bara $34.8 \%$ dan gas alam 19.8\% (BP Statistical Review 2015). Cadangan terbukti minyak bumi sebesar 3.6 miliar barel, gas bumi sebesar 100.3 TCF dan cadangan batubara sebesar 31.35 miliar ton jika diasumsikan tidak ditemukan penemuan baru maka minyak bumi akan habis dalam 13 tahun, gas bumi 34 tahun dan batubara 72 tahun (BPPT 2015). Permasalahan krisis energi fosil di masa depan memerlukan solusi yang tepat dengan pendekatan yang komprehensif. Peningkatan pemanfaatan sumber energi baru dan terbarukan (EBT) dapat menjadi solusi sebagai langkah untuk mengatasi ketergantungan terhadap energi fosil (BALIHRISTI 2011). Peraturan Pemerintah No. 79 Tahun 2014 Tentang Kebijakan Energi Nasional (KEN) mengamanatkan, agar dapat mencapai bauran energi primer yang optimal maka diperlukan kontribusi dari energi baru dan terbarukan sebesar 23\% pada tahun 2025. Implikasi kebijakan ini diperlukan untuk percepatan dalam pengembangan EBT (Sugiyono 2016). 
Peran energi baru dan terbarukan juga dapat mengurangi emisi gas rumah kaca (GRK) yang dirilis ke udara, tanah dan air. Tiga GRK utama adalah karbondioksida $\left(\mathrm{CO}_{2}\right)$, metana $\left(\mathrm{CH}_{4}\right)$, nitrogen oksida $\left(\mathrm{N}_{2} \mathrm{O}\right)$ (EPA 2015). Sumber GRK sebagian besar berasal dari pembakaran dan pengangkutan bahan bakar fosil, limbah padat maupun limbah cair (Bappenas 2014; EPA 2015). Penggunaan bahan bakar berbasis energi fosil menyumbang sekitar $60 \%$ dari total emisi gas rumah kaca global atas perubahan iklim (UN 2015). Bahan bakar fosil menghasilkan emisi GRK yang dapat mengancam iklim global, lingkungan, kesehatan manusia dan bumi (Wamuyu 2014).

Salah satu jenis energi terbarukan yang berpotensi dikembangkan di Indonesia adalah bioenergi. Bioenergi adalah sumber energi terbarukan yang berasal dari biomassa seperti kelapa sawit, kelapa, tebu, ubi kayu, sagu, jarak pagar, kemiri sunan, nyamplung, aren, limbah pertanian, limbah industri, limbah ternak dan limbah perkotaan (Balitbang Pertanian 2014; Zafar 2018). Bioenergi berkontribusi untuk mengurangi gas rumah kaca, ketahanan energi, pembangunan sosial dan ekonomi masyarakat pedesaan dan serta meningkatkan pengelolaan sumber daya dan limbah (IEA 2009). Bioenergi merupakan sumber energi terbarukan yang memasok sekitar 6\% bauran energi nasional (KESDM 2016).

Salah satu jenis bioenergi yang dapat dikembangkan adalah biogas. Biogas dihasilkan melalui proses fermentasi bahan-bahan organik seperti limbah ternak, limbah pertanian, tanaman air, limbah industri pertanian (limbah cair tahu, kelapa sawit, tapioka), limbah rumahtangga dan perkotaan (seperti sampah rumahtangga, kotoran manusia dan lain-lain) (KESDM 2014). Pengembangan biogas merupakan bentuk penyediaan energi bersih untuk masyarakat. Energi biogas dianggap sebagai solusi berkelanjutan untuk kebutuhan energi lokal (Wamuyu 2014). Implementasi biogas dapat mendukung aksi mitigasi penurunan emisi $26 \%$ pada tahun 2020 serta mendukung tujuan Sustainable Development Goals yaitu mencapai energi berkelanjutan pada tahun 2030 (Bappenas 2011; Akenji dan Bengtsson 2014). Biogas menyediakan energi yang murah bagi masyarakat pedesaan yang kurang memiliki akses terhadap energi konvensional (Chavez 2015; Souza dkk. 2015). Pengoptimalan potensi desa melalui pengembangan energi terbarukan dapat mendukung peningkatan perekonomian desa. Potensi ekonomi tertinggi desa adalah potensi energi terbarukan sebesar $86.4 \%$ (KDPDTT 2016).

Pengembangan energi terbarukan di pedesaan dapat mewujudkan kemandirian energi pedesaan. Kajian mengenai peran energi terbarukan biogas diperlukan untuk mewujudkan kemandirian energi pedesaan yang berkelanjutan. Tujuan dari penelitian ini adalah
1. Menganalisis status keberlanjutan biogas limbah tahu pedesaan

2. Menganalisis efektivitas biogas sebagai energi alternatif rumahtangga pedesaan

\section{Metode Penelitian}

\subsection{Lokasi dan Waktu Penelitian}

Lokasi penelitian dilaksanakan di Desa Kalisari, Kecamatan Cilongok, Kabupaten Banyumas, Jawa Tengah. Desa Kalisari merupakan desa industri tahu dengan jumlah UKM sebanyak 260 UKM. Penelitian dilaksanakan sejak bulan September 2017 sampai November 2017.

\subsection{Pengambilan Data}

Metode pengambilan data dilakukan dengan cara sengaja (purposive sampling). Jumlah responden 40 orang yang berprofesi sebagai pengrajin tahu yang mendapatkan biogas serta 7 orang yang berperan sebagai informan kunci. Informan kunci tersebut adalah kepala desa, kepala dusun, 1 orang ketua kelompok biogas swadaya, 3 orang ketua kelompok biogas non swadaya, serta 1 orang pengelola. Data yang dikumpulkan merupakan data primer. Data primer diperoleh melalui kuesioner dan wawancara mendalam (indepth interview).

\subsection{Analisis Data}

Data yang telah diperoleh kemudian dianalisis berdasarkan tujuan penelitian. Analisis data dalam penelitian ini dijelaskan sebagai berikut.

\subsubsection{Analisis Status Keberlanjutan Biogas Limbah Tahu Pedesaan}

Analisis status keberlanjutan biogas limbah tahu pedesaan menggunakan metode analisis ordonansi Rapfish (Rapid Appraisal for Fisheries) melalui pendekatan Multidimensional Scaling (MDS). MDS adalah teknik untuk menganalisis kemiripan atau ketidakmiripan data pada satu set objek dalam bentuk peta (Alder dkk. 2000; Borg dan Groenen 2005). MDS dapat digunakan untuk memodelkan melalui hubungan jarak antar titik pada suatu ruang yang direpresentasikan secara geometris (Young 1987; Borg dan Groenen 2005). Lima dimensi keberlanjutan yang digunakan dalam penelitian ini yaitu dimensi sosial ( 8 atribut), dimensi ekonomi (6 atribut), dimensi ekologi (7 atribut), dimensi kelembagaan (6 atribut) dan dimensi teknologi (7 atribut) (Tabel 1). Data kemudian diolah menggunakan rapfish untuk mendapatkan status keberlanjutan biogas limbah tahu pedesaan. Menurut Alder dkk. (2000) tahapan data dalam analisis status berkelanjutan adalah:

1. Penentuan atribut

2. Pemberian skor pada kriteria atribut

3. Analisis ordonansi MDS pada setiap atribut untuk menilai indeks dan status keberlanjutan 
4. Penilaian indeks dan status keberlanjutan pada setiap dimensi. Kategori nilai terdiri dari 4 kategori, jika nilai indeks 0.00-25.0 memiliki kategori tidak berkelanjutan. Nilai indeks 25.01-50.00 memiliki kategori kurang kurang berkelanjutan. Nilai indeks 50.0175.00 memiliki kategori cukup berkelanjutan dan nilai indeks 75.01-100.0 berkategori sangat berkelanjutan

5. Analisis sensitivitas (leverage analysis) untuk mengidentifikasi atribut yang paling sensitif yang berpengaruh terhadap indeks keberlanjutan

6. Analisis Monte Carlo untuk melihat pengaruh kesalahan dalam pembuatan skor pada setiap atribut di masing-masing dimensi dengan selang kepercayaan $95 \%$

7. Penilaian ketetapan (goodness of fit) dilakukan untuk melihat besaran nilai stress atau $\mathrm{R}^{2}$. Model yang baik ditujukan dengan nilai stress yang lebih kecil dari 0.25 dan $\mathrm{R}^{2}$ yang mendekati 1.

Tabel 1. Atribut Keberlanjutan Biogas Limbah Tahu di Desa Kalisari

\begin{tabular}{|c|c|}
\hline Dimensi & Atribut \\
\hline Ekonomi & $\begin{array}{l}\text { 1. Penghematan bahan bakar } \\
\text { 2. Beban pengeluaran rumah tangga } \\
\text { 3. Penciptaan peluang usaha baru } \\
\text { 4. Pengeluaran biaya perawatan } \\
\text { 5. Pemanfaatan hasil samping limbah tahu } \\
\text { 6. Pemanfaatan untuk kebutuhan lain }\end{array}$ \\
\hline Kelembagaan & $\begin{array}{l}\text { 1. Dukungan pemerintah kepada pengelola } \\
\text { 2. Dukungan pengelola kepada anggota } \\
\text { 3. Aturan kelompok/pengelola } \\
\text { 4. Pembagian tugas dan peran pengelola } \\
\text { 5. Organisasi pengelola } \\
\text { 6. Hubungan antar pengelola dengan anggota }\end{array}$ \\
\hline Teknologi & $\begin{array}{ll}\text { 1. } & \text { Kondisi instalasi } \\
\text { 2. Umur aktif penggunaan instalasi } \\
\text { 3. Pengetahuan tentang teknologi biogas } \\
\text { 4. Kondisi saluran rumahtangga } \\
\text { 5. Penyediaan kompor } \\
\text { 6. } \\
\text { 7. } & \text { Petersediaan limbah } \\
\end{array}$ \\
\hline
\end{tabular}

Atribut-atribut tersebut di atas dijadikan kriteria untuk menilai keberlanjutan sebab menurut Buchholz dkk. (2009) penilaian keberlanjutan dapat disesuaikan dengan wilayah geografis maupun skala yang menjadi fokus penilaiannya. Hal ini dikarenakan kriteria penilaian mungkin berbeda dari satu kasus ke kasus lain namun begitu ada beberapa kriteria atau atribut yang biasa dijadikan dalam penilaian keberlanjutan bioenergi antara lain emisi gas rumah kaca, perlindungan terhadap ekosistem tanah, air maupun udara, ketahanan energi, partisipasi masyarakat, pengelolaan limbah, kohesi sosial, dampak pencemaran terhadap estetika lingkungan serta beberapa penilaian secara ekonomi.

\subsubsection{Analisis Efektivitas Biogas Sebagai Energi Alternatif Rumahtangga Pedesaan}

Analisis data untuk mendapatkan gambaran mengenai efektivitas biogas sebagai energi alternatif rumahtangga pedesaan menggunakan beberapa aspek yaitu aspek secara sosial, ekonomi dan ekologi. Pengolahan data pada aspek sosial menggunakan metode analisis deskriptif untuk mendapatkan gambaran mengenai keefektivitasan biogas secara sosial dari sisi gender dan resolusi konflik. Pengolahan data pada aspek ekonomi-ekologi digunakan untuk mendapatkan manfaat tangible dan intangible dari adanya biogas limbah tahu. Manfaat tangible dalam penelitian ini yaitu nilai penghematan bahan bakar setelah adanya biogas. Metode yang digunakan adalah metode perubahan pendapatan sebagai berikut

$$
\Delta \mathrm{Q}=\mathrm{Q} 1-\mathrm{Q} 2
$$

\section{Keterangan:}

$\Delta \mathrm{Q}=$ Selisih jumlah penggunaan elpiji ( $\mathrm{Rp})$

Q1 = Jumlah penggunaan elpiji sebelum 
menggunakan biogas (Rp)

= Jumlah penggunaan elpiji sesudah menggunakan biogas (Rp)

Sementara manfaat intangible yaitu nilai kesediaan masyarakat (Willingness To Pay) untuk mengganti elpiji $3 \mathrm{~kg}$ menjadi biogas serta nilai penghematan reduksi emisi karbon dari pengurangan penggunaan elpiji $3 \mathrm{~kg}$. Metode yang digunakan sebagai berikut.

$\mathrm{EWTP}=\sum_{i=1}^{n} W i . \mathrm{Pfi}$

Keterangan:

$\begin{array}{ll}\text { EWTP } & =\text { Dugaan rataan WTP } \\ \mathrm{Wi} & =\text { Nilai WTP ke-i } \\ \mathrm{Pfi} & =\text { Frekuensi relatif } \\ \mathrm{n} & =\text { Jumlah responden } \\ \mathrm{i} & =\text { Responden ke-i yang bersedia melakukan } \\ & \text { pembayaran jasa lingkungan }\end{array}$

Metode yang digunakan untuk menghitung nilai pengurangan emisi karbon akibat penggunaan elpiji menggunakan pendekatan dari Intergovernmental Panel On Climate Change (IPCC) sebagai berikut

Emisi $\mathrm{CO}_{2}=\mathrm{a} \times \mathrm{EF}_{\mathrm{CO} 2} \times \mathrm{NCV}_{\mathrm{LP}}$

Keterangan:

$\begin{array}{ll}\text { Emisi } \mathrm{CO}_{2} & =\text { Total emisi } \mathrm{CO}_{2} \text { (g karbon) } \\ \mathrm{a} & =\text { Konsumsi LPG }(\mathrm{kg}) \\ \mathrm{EFCO}_{2} & =\text { Faktor emisi LPG 63,1 g } \\ & \text { Carbon } / \mathrm{MJ} \\ \mathrm{NCV}_{\mathrm{LPG}} & =\end{array}$

\section{Hasil dan Pembahasan}

\subsection{Status Keberlanjutan Biogas Limbah Tahu}

3.1.1. Nilai Indeks Keberlanjutan Dimensi Sosial Hasil analisis MDS terhadap delapan atribut pada dimensi sosial menghasilkan nilai indeks keberlanjutan yaitu 61.12. Status keberlanjutan pada dimensi ini adalah cukup berkelanjutan.

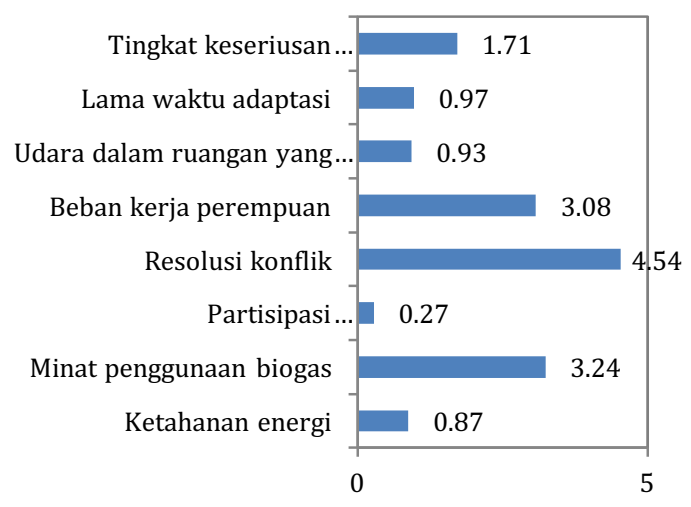

Gambar 1. Atribut Sensitif Dimensi Sosial
Hasil analisis atribut-atribut sensitif yang berpengaruh dalam mendukung keberlanjutan pengembangan biogas limbah tahu pada dimensi sosial (Gambar 1) yaitu beban kerja perempuan (3.08), resolusi konflik (4.54) dan minat penggunaan biogas (3.24). Atribut-atribut sensitif tersebut sangat menentukan keberlanjutan biogas limbah tahu di Desa Kalisari. Ketiga atribut tersebut saling berkaitan serta merupakan faktor paling utama dalam memberikan dampak sosial yang positif. Biogas di Desa Kalisari telah memberikan keuntungan secara sosial karena membantu meringankan kerja perempuan sebab mereka tidak perlu menyiapkan tungku kayu bakar untuk menghasilkan api. Biogas membantu kegiatan memasak menjadi lebih praktis, bersih dan cepat. Limbah tahu yang semula mencemari sungai menyebabkan konflik antara kelompok petani dan pengrajin tahu sebab limbah tahu menyebabkan penurunan produktivitas pertanian. Limbah tahu yang diolah menjadi biogas menjadi sarana akomodasi konflik antara petani dan pengrajin tahu sebab tingkat pencemaran di sungai menjadi berkurang sehingga produktivitas pertanian dapat kembali menjadi normal. Keuntungankeuntungan tersebut yang membuat masyarakat mempunyai minat yang tinggi terhadap biogas.

\subsubsection{Nilai Indeks Keberlanjutan Dimensi Ekonomi}

Hasil analisis MDS pada dimensi ekonomi menunjukkan nilai indeks yaitu 50.37 yang tergolong pada kategori cukup berkelanjutan. Nilai indeks tersebut mendekati kategori kurang berkelanjutan sehingga perlu dikelola dengan baik agar dapat meningkatkan status keberlanjutan.

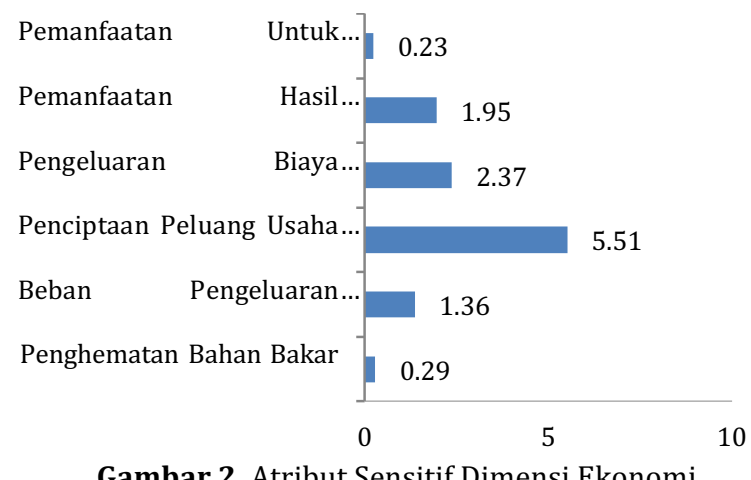

Atribut sensitif yang mempengaruhi dimensi ekonomi (Gambar 2) adalah penciptaan peluang usaha baru (5.51). Biogas tidak membantu masyarakat Desa Kalisari membuka usaha baru seperti warung makan. Hal ini disebabkan api yang dihasilkan dari biogas di Desa Kalisari bertekanan rendah sehingga menghasilkan api yang kecil.

\subsubsection{Nilai Indeks Keberlanjutan Dimensi Ekologi}

Hasil analisis MDS terhadap tujuh atribut dimensi ekologi adalah 63.20 yang artinya berkategori cukup berkelanjutan. Analisis atribut- 
atribut sensitif menghasilkan 3 atribut yang mempengaruhi keberlanjutan dimensi ekologi.

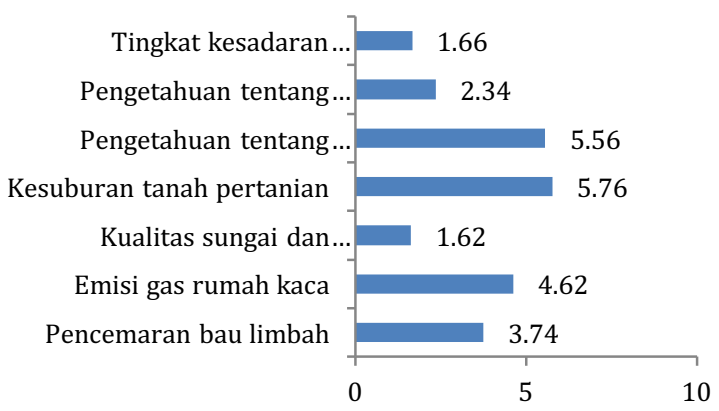

Gambar 3. Atribut Sensitif Dimensi Ekologi

Atribut-atribut sensitif pada dimensi ekologi (Gambar 3) yaitu kesuburan tanah pertanian (5.76), pengetahuan tentang manfaat pengelolaan limbah (3.74), emisi gas rumah kaca (4.62) dan pencemaran bau limbah (3.74). Biogas di Desa Kalisari sangat membantu dalam perbaikan lingkungan sebab sebelum biogas diimplementasikan, masyarakat Desa Kalisari mengalami kerugian-kerugian secara ekologi diantaranya menghirup bau tak sedap dari limbah cair tahu yang masuk aliran sungai, menurunkan kesuburan tanah pertanian yang berdampak pada penurunan produktivitas pertanian serta berpotensi menurunkan emisi gas rumah kaca. Biogas berperan dalam pemulihan manfaat yang berasal dari limbah tahu. Atribut-atribut tersebut merupakan faktor kunci keberlanjutan biogas limbah tahu pada dimensi ekologi.

\subsubsection{Nilai Indeks Keberlanjutan Dimensi Kelembagaan}

Hasil MDS menunjukkan nilai indeks yaitu 57.82 yang temasuk kategori cukup berkelanjutan. Atributatribut sensitif pada dimensi terdapat 2 atribut seperti yang ditampilkan pada (Gambar 4).

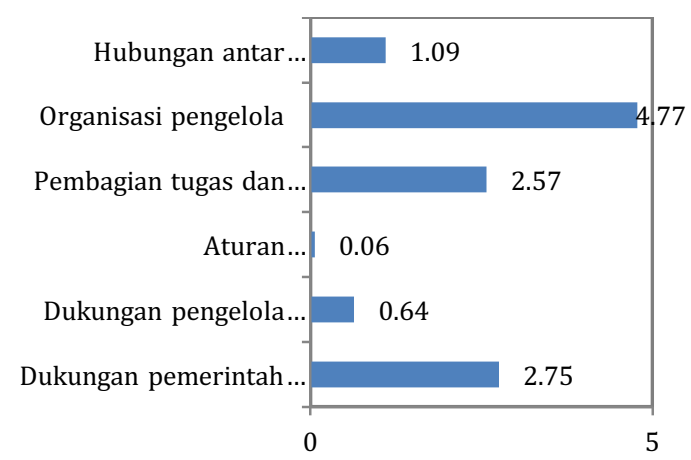

Gambar 4. Atribut Sensitif Dimensi Kelembagaan

Atribut-atribut sensitif tersebut organisasi pengelola (2.75), pembagian tugas dan peran pengelola (2.57). Biogas limbah tahu di Desa Kalisari mengalami kendala secara kelembagaan karena pengelolaan di bawah kelompok biogas dipandang kurang efektif. Anggota dalam kelompok biogas yang diberikan peran tidak melaksanakan tugas sebagaimana kewajibannya yang akhirnya berdampak pada tak terawatnya biogas.

\subsubsection{Nilai Indeks Keberlanjutan Dimensi Teknologi}

Nilai indeks keberlanjutan pada dimensi teknologi adalah 43.31. Nilai tersebut menunjukkan bahwa secara teknologi biogas limbah tahu di Desa Kalisari berstatus kurang berkelanjutan.

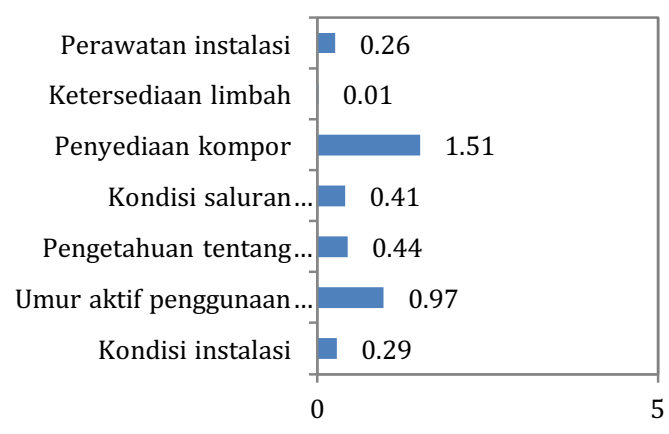

Gambar 5. Atribut Sensitif Dimensi Teknologi

Atribut-atribut sensitif pada dimensi ini adalah penyediaan kompor (1.51) dan umur aktif penggunaan instalasi (0.97). Atribut tersebut menjadi atribut sensitif karena kurangnya perawatan dan pemeliharaan komponen jaringan dan instalasi. Minimnya perawatan serta pemeliharaan tersebut disebabkan faktor kurangnya dana dan kelompok yang tidak berjalan secara optimal.

Perbandingan nilai indeks keberlanjutan antar dimensi dapat dilihat pada diagram layanglayang. Gambar 6 menampilkan perbandingan nilai indeks keberlanjutan biogas limbah tahu di Desa Kalisari

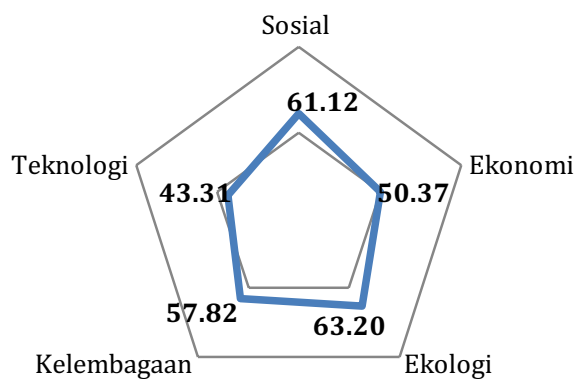

Gambar 6. Perbandingan Nilai Indeks Keberlanjutan Biogas Limbah Tahu di Desa Kalisari

Setelah analisis setiap dimensi dilakukan, analisis secara multidimensi yaitu dimensi sosial, ekonomi, ekologi, kelembagaan dan teknologi menghasilkan nilai indeks keberlanjutan sebesar 56.16 yang menunjukkan bahwa keberlanjutan biogas limbah tahu di Desa Kalisari berada pada status cukup berkelanjutan. Ringk asan nilai indeks keberlanjutan pada setiap dimensi dan multidimensi disajikan pada Tabel 2 
Tabel 2. Nilai Indeks Keberlanjutan Biogas Limbah Tahu di Desa Kalisari

\begin{tabular}{cc}
\hline Dimensi & MDS \\
\hline Sosial & 61.12 \\
Ekonomi & 50.37 \\
Ekologi & 63.20 \\
Kelembagaan & 57.82 \\
Teknologi & 43.31 \\
Multidimensi & $\mathbf{5 6 . 1 6}$ \\
\hline
\end{tabular}

\subsubsection{Analisis Monte Carlo}

Fauzi dan Anna (2002) mengemukakan bahwa teknik Monte Carlo merupakan metode simulasi untuk mengevaluasi dampak dari kesalahan acak (random error) terhadap seluruh dimensi. Hasil analisis MDS dengan Monte Carlo, nilai stress dan $\mathrm{R}^{2}$ disajikan pada Tabel 3

Analisis Monte Carlo biogas limbah tahu di Desa Kalisari pada selang kepercayaan 95\% menunjukkan tidak adanya perbedaan yang signifikan. Hal tersebut berarti semua atribut yang diberikan pada status keberlanjutan biogas limbah tahu di Desa Kalisari cukup akurat dan dapat dipertanggungjawabkan karena memiliki nilai stress kurang dari 0.25 dan nilai koefisien determinasi $\left(\mathrm{R}^{2}\right)$ kurang dari 1.

\subsection{Efektivitas Biogas Sebagai Energi Alternatif Rumahtangga Pedesaan}

Biogas limbah tahu digunakan oleh masyarakat Desa Kalisari untuk mencukupi kebutuhan memasak sebagai pengganti elpiji $3 \mathrm{~kg}$ dan kayu bakar. Biogas membantu masyarakat pedesaan dalam penghematan bahan bakar telah dihasilkan dari berbagai penelitian terdahulu seperti penelitian yang dilakukan oleh Wamuyu (2014) di Kenya bahwa sebesar 73\% keuntungan biogas adalah menghemat pengeluaran untuk pembelian bahan bakar. Penelitian oleh Ali dkk. (2013) bahwa bagi negara berkembang, biogas merupakan alternatif untuk menghasilkan energi yang berkelanjutan bagi rumahtangga pedesaan karena biogas dapat menghemat biaya serta ramah lingkungan. Penelitian lain yang dilakukan oleh Phonephachah (2012) bahwa penerapan biogas pedesaan di Laos dapat menghemat pembelian bahan bakar sebesar Rp 133 510/bulan.

Penelitian oleh Rahmani dkk. (2013) di DKI Jakarta bahwa pemanfaatan biogas dapat mengurangi konsumsi elpiji dan minyak tanah secara signifikan. Biogas di Desa Kalisari dapat membantu masyarakat menghemat pembelian elpiji $3 \mathrm{~kg}$. Presentase penghematan tersebut mencapai $43 \%$. Nilai penghematan elpiji masyarakat Desa Kalisari per tahun disajikan dalam Tabel 4.

Tabel 3. Perbedaan MDS dengan Monte Carlo, Nilai Stress dan $\mathrm{R}^{2}$

\begin{tabular}{cccccc}
\hline Dimensi & MDS & Monte Carlo & Perbedaan & Stress & $\mathbf{R}^{\mathbf{2}}$ \\
\hline Sosial & 61.12 & 60.18 & 0.94 & 60.18 & 0.94 \\
Ekonomi & 50.37 & 50.95 & 0.58 & 50.95 & 0.58 \\
Ekologi & 63.20 & 62.27 & 0.93 & 62.27 & 0.93 \\
Kelembagaan & 57.82 & 57.92 & 0.10 & 57.92 & 0.10 \\
Teknologi & 43.31 & 42.98 & 0.33 & 42.98 & 0.33 \\
\hline
\end{tabular}

Tabel 4. Nilai Penghematan Elpiji Masyarakat Desa Kalisari/tahun

\begin{tabular}{cccc}
\hline \multirow{2}{*}{ Jumlah Responden } & \multicolumn{2}{c}{ Rata-rata Nilai Konsumsi Elpiji (tahun) } & \multirow{2}{*}{ Selisih (tahun) } \\
\cline { 2 - 3 } & Sebelum Biogas (tahun) & Setelah Biogas (tahun) & Rp 8713200 \\
\hline 40 & Rp 20064000 & Rp 11350800 & Rp 1943043600 \\
\hline
\end{tabular}

Estimasi rata-rata nilai konsumsi elpiji $3 \mathrm{~kg}$ sebelum penggunaan biogas adalah $20 \quad 064$ 000/tahun. Sesudah adanya biogas, nilai konsumsi elpiji 3 kg yaitu Rp 11350 800/tahun. Selisih penghematan yang diperoleh adalah $\mathrm{Rp} \quad 8 \quad 713$ 200/tahun. Pengguna biogas di Desa Kalisari mencapai 223 rumahtangga (RT). Maka nilai penghematan penggunaan elpiji masyarakat Desa Kalisari mencapai Rp 1943 043 600/tahun. Nilai ekonomi tersebut dapat mendukung ketahanan ekonomi lokal sekaligus kemandirian energi pedesaan. Hal ini menunjukkan bahwa masyarakat Desa Kalisari dapat menyimpan sebagian uang yang tidak perlu dikeluarkan dalam pembelian elpiji sehingga dapat dialokasikan untuk pengeluaran lain.

Biogas secara ekologi membantu menurunkan emisi GRK karena biogas berperan sebagai pengganti elpiji ukuran $3 \mathrm{~kg}$. Peranan biogas dalam menekan laju emisi $\mathrm{CO}_{2}$ merupakan manfaat intangible dari biogas limbah tahu. Tabel 5 menyajikan nilai manfaat intangible dari reduksi emisi dari elpiji $3 \mathrm{~kg}$ akibat penggunaan biogas 
Tabel 5. Manfaat Intangible Reduksi Emisi Setelah Penggunaan Biogas

\begin{tabular}{ccccc}
\hline Produk & $\begin{array}{c}\mathrm{CO}_{2} \text { (ton) } \\
(\mathrm{a})\end{array}$ & $\begin{array}{c}\text { Jumlah Konsumsi } \\
\text { (tahun }) \\
(\mathrm{b})\end{array}$ & $\begin{array}{c}\text { Jumlah Konsumsi } \\
\text { (rumahtanga) } \\
(\mathrm{c})\end{array}$ & $\begin{array}{c}\text { Manfaat Intangible } \\
\left(\mathrm{d}=\mathrm{a}^{*} \mathrm{~b}^{*} \mathrm{c}\right)^{*} 105 \text { US\$4 }\end{array}$ \\
\hline Gas elpiji $3 \mathrm{~kg}$ & $0.009^{5}$ & 24 & 223 & Rp 70 812 000 \\
\hline \multicolumn{5}{c}{ Dalam Rupiah (1 US\$ = Rp. 14.000) } \\
\hline \multicolumn{5}{c}{}
\end{tabular}

\footnotetext{
${ }^{4}$ Biaya sosial karbon menurut Environmental Protection Agency (2016)

${ }^{5}$ Emisi karbon yang dihasilkan dari pembakaran gas elpiji $3 \mathrm{~kg}$ menurut Intergovernmental Panel on Climate Change (2006)
}

Emisi $\mathrm{CO}_{2}$ yang dihasilkan dari pembakaran elpiji $3 \mathrm{~kg}$ adalah 0.009 ton. Rata-rata penggunaan elpiji 3 kg masyarakat Desa Kalisari sebelum adanya biogas adalah 4 tabung/bulan/rumahtangga, namum setelah adanya biogas masyarakat Desa Kalisari mampu menghemat penggunaan elpiji $3 \mathrm{~kg}$ menjadi 2 tabung/bulan/rumahtangga. Jumlah pengguna biogas di Desa Kalisari adalah 223 RT. Nilai manfaat yang diperoleh adalah Rp 70812 000/tahun. Nilai tersebut menunjukkan bahwa masyarakat dapat menghemat biaya sosial yang harus ditanggung akibat pencemaran emisi $\mathrm{CO}_{2}$ yang dihasilkan dari pembakaran elpiji $3 \mathrm{~kg}$

Manfaat intangible lain dari adanya biogas limbah tahu adalah kesediaan membayar responden untuk mengganti bahan bakar gas elpiji 3 kg dengan biogas. Tabel 6 menyajikan perhitungan kesediaan membayar responden.

Tabel 6. Nilai Kesediaan Responden Untuk Berkontribusi Pada Pemanfaatan Biogas

\begin{tabular}{|c|c|c|c|}
\hline $\begin{array}{l}\text { Nilai Kesediaan } \\
\text { (Rp/liter) }\end{array}$ & Responden & Persentase (\%) & $\begin{array}{c}\text { Nilai Rata-rata Kesediaan } \\
\text { (Rp/liter/bulan) }\end{array}$ \\
\hline 10.000 & 4 & 10 & 1000 \\
\hline 15.000 & 21 & 52.5 & 7875 \\
\hline 20.000 & 13 & 32.5 & 6500 \\
\hline 25.000 & 2 & 5 & 1250 \\
\hline Jumlah & 40 & $100 \%$ & 16625 \\
\hline \multicolumn{3}{|c|}{ Jumlah pengguna biogas (223 RT) } & Rp 44488 500/tahun \\
\hline
\end{tabular}

Masyarakat diberikan penawaran untuk membayar iuran per bulan untuk penggunaan biogas sebagai pengganti elpiji $3 \mathrm{~kg}$ sebesar mulai dari Rp 10 000 hingga Rp 25 000. Kemampuan membayar responden di dominasi pada besaran Rp 15000 . Berdasarkan perhitungan pada Tabel 6 tersebut nilai rata-rata kesediaan membayar responden adalah $\mathrm{Rp}$ 16 625/liter/bulan. Jumlah pengguna biogas di Desa Kalisari adalah 223 RT. Maka nilai kesediaan responden pemanfaat biogas yang diperoleh sebesar Rp 44488 500/tahun. Nilai tersebut merupakan keinginan membayar masyarakat untuk menekan laju pencemaran limbah tahu melalui pemanfaatan biogas. total nilai manfaat dari pemanfaatan biogas di Desa Kalisari disajikan pada Tabel 7.

Tabel 7. Total Nilai Manfaat Pemanfaatan Biogas di Desa Kalisari

\begin{tabular}{clc}
\hline Manfaat & \multicolumn{1}{c}{ Bentuk } & $\begin{array}{c}\text { Nilai Manfaat } \\
\text { (tahun) }\end{array}$ \\
\hline Tangible & $\begin{array}{l}\text { Penghematan bahan bakar } \\
\text { elpiji 3 kg }\end{array}$ & Rp 1943 043 600 \\
Intangible & $\begin{array}{l}\text { Reduksi emisi dari } \\
\text { pembakaran elpiji 3 kg } \\
\text { Kesediaan membayar } \\
\text { responden untuk } \\
\text { mengganti elpiji 3 kg } \\
\text { menjadi biogas }\end{array}$ & Rp 70 812 000 \\
\hline Total & Rp 44 488 500 $2 \mathbf{0 5 8 ~ 3 4 4 ~ 1 0 0}$ \\
\hline
\end{tabular}

Nilai manfaat ekonomi total yang dapat dinikmati masyarakat Desa Kalisari melalui penghematan bahan bakar, reduksi emisi $\mathrm{CO}_{2}$ serta kesediaan membayar untuk mengganti elpiji menjadi biogas mencapai Rp 2058344 100/tahun.

Efektivitas biogas tidak hanya dapat dilihat secara ekonomi dan ekologi. Biogas dipandang efektif dalam mengurangi beban kerja perempuan dalam kegiatan memasak. Upaya perempuan dalam mempersiapkan waktu yang lama untuk kegiatan memasak membuat perempuan tidak dapat terlibat dalam kegiatan ekonomi atau kegiatan lain yang memberdayakan (Chinigo dan Kingiri 2013). Peran perempuan dalam pelaksanaan manajemen dan perawatan instalasi biogas maupun kepengurusan biogas di Desa Kalisari memang tidak ada, namun perempuan menjadi pihak yang paling mendapatkan manfaat karena memudahkan mereka dalam pekerjaan memasak, khususnya bagi rumahtangga pengguna kayu bakar.

Biogas juga berperan sebagai sarana akomodasi konflik antar masyarakat. Pencemaran limbah diketahui dapat menyebabkan konflik lingkungan antar golongan masyarakat seperti penelitian yang dilakukan oleh Jumiati dan Dahlia (2011) terjadinya konflik antara Pabrik Gula (PG) Tasikmadu, Kabupaten Karanganyar dengan 
masyarakat Desa Triyagan, Kabupaten Sukoharjo dikarenakan masyarakat merasa terganggu akibat limbah padat maupun limbah cair yang menyebabkan polusi udara dan menyebabkan gatal-gatal pada kulit. Konflik yang terjadi antara petani dengan pengrajin tahu di Desa Kalisari dikarenakan limbah cair yang masuk ke sistem irigasi pertanian sehingga mencemari sawah yang berdampak pada menurunnya produktivitas pertanian sekitar 20\%. Biogas menjadi solusi atas konflik yang terjadi sebab melalui biogas kondisi sungai untuk saluran irigasi sebesar $80 \%$ sudah membaik serta produktivitas pertanian telah kembali pada kondisi normal.

\section{Kesimpulan dan Saran}

Berdasarkan hasil penelitian yang dilakukan maka kesimpulan yang diperoleh yaitu:

a) Status berkelanjutan biogas limbah tahu pada dimensi sosial, ekonomi, ekologi dan kelembagaan adalah cukup berkelanjutan sedangkan pada dimensi teknologi berstatus kurang berkelanjutan. Faktor yang mempengaruhi status cukup berkelanjutan pada 4 dimensi tersebut adalah biogas menyediakan energi bersih dan murah sehingga masyarakat saat ini dapat mengurangi ketergantungan penggunaan gas elpiji $3 \mathrm{~kg}$ yang keberadaannya semakin langka serta harganya cukup mahal bagi masyarakat pedesaan. Selain itu, solusi pencemaran bau limbah tahu saat ini hanya dapat diatasi oleh instalasi biogas sehingga ke depannya masyarakat optimis mengembangkan biogas limbah tahu sebagai energi alternatif mereka. Sementara faktor yang mempengaruhi status kurang berkelanjutan pada dimensi teknologi adalah kesulitan masyarakat desa dalam mengakses teknologi tersebut. Minimnya pengetahuan masyarakat desa dalam menerima teknologi menjadi kendala dalam pengoperasian maupun pemeliharaan.

b) Total manfaat ekonomi biogas limbah tahu mencapai Rp 2058344 100/tahun namun, nilai tersebut dianggap belum efektif sebab jika diasumsikan seluruh rumahtangga di Desa Kalisari menerima biogas, saat ini biogas secara ekonomi hanya dapat memenuhi sebesar 18\% rumahtangga dari keseluruhan rumahtangga di Desa Kalisari. Sementara secara sosial, biogas efektif mengurangi beban kerja perempuan dan sebagai resolusi konflik antara petani dengan pengrajin tahu.

\section{Saran}

Saran bagi pengembangan bioenergi pedesaan khususnya biogas limbah tahu di Desa Kalisari antara lain:

- Pemerintah Kabupaten Banyumas, Dinas Lingkungan Hidup (DLH) Kabupaten Banyumas ataupun Badan Pengkajian dan Penerapan Teknologi (BPPT) hendaknya mengadakan bimbingan teknis secara berkala untuk meningkatkan skill masyarakat dalam mengakses teknologi serta memfasilitasi penyediaan teknologi.

- Penanganan api biogas yang kecil dapat dioptimalkan melalui pembuatan bak penangkap. Pembuatan bak penangkap bertujuan untuk menampung limbah sementara sebelum masuk ke bak penampung sehingga apabila kapasitas limbah bertambah akan memasok api lebih banyak dan tidak ada limbah yang terbuang ke sungai akibat penuhnya bak penampung.

- Pada aspek kelembagaan dilakukan dengan mengintegerasikan pengelolaan biogas dalam struktur Badan Usaha Milik Desa (BUM Desa), sesuai dengan Undang-Undang No. 06 Tahun 2014 Tentang Desa bahwa pengelolaan sumberdaya alam di desa dapat diusahakan BUM Desa. Kepengurusan biogas limbah tahu di bawah naungan BUM Desa dapat menambah pendapatan asli desa. Kepengurusan biogas dalam BUM Desa dianggap ideal karena setiap pengurus berhak menerima insentif. Selain itu, BUM Desa dapat mendapatkan hibah/akses pemodalan dari pemerintah pusat maupun daerah yang dapat digunakan untuk perbaikan jaringan dan instalasi.

\section{DAFTAR PUSTAKA}

Akenji L, Bengtsson M. 2014. Making Sustainable Consumption And Production The Core of The Sustainable Development Goals. Jepang: Institute For Global Environmental Study.

Alder J, Pitcher TJ, Preikshot D, Kaschner K, Ferriss B. 2000. How Good is Good?: A Rapid Appriasal Technique for Evaluation of the Sustainability Status Fisheries of the North Atlantic. Di dalam Pauly D, Pitcher TJ, editor. Methods for Assessing the Impact of Fisheries on Marine Ecosystems of the North Atlantic. Fisheries Centre Research Reports, 8(2): 136-182.

Ali S, Zahra N, Nasreen Z, Usman S. 2013. Impact of Biogas Technology in the Development of Rural Population. Journal of Analytical and Environmental Chemistry, 14 (2): 65-74.

Badan Lingkungan Hidup, Riset dan Teknologi Informasi. 2011. Pengembangan Desa Mandiri Energi di Provinsi Gorontalo. Gorontalo: Balihristi

Badan Perencanaan Pembangunan Nasional. 2011. Pedoman Kaji Ulang Rencana Aksi Daerah Penurunan Emisi Gas Rumah Kaca. Jakarta: Kementerian Perencanaan Pembangunan Nasional.

Badan Perencanaan Pembangunan Nasional. 2014. Perhitungan Baseline Emisi Gas Rumah Kaca Sektor Pengelolaan Limbah. Jakarta: Kementerian Perencanaan Pembangunan Nasional.

Badan Penelitian dan Pengembangan Pertanian. 2014. Evaluasi Kebijakan Pengembangan Bieoenergi di Sektor Pertanian. Jakarta: Pusat Sosial Ekonomi dan Kebijakan Pertanian 
Borg I, Groenen PJF. 2005. Modern Multidimensional Scaling. Amerika Serikat: Springer.

BP Statistical Review 2015. 2015. Pasar Energi di Indonesia 2014 [Internet]. [Diunduh 2016 Apr 14]. Tersedia pada: http://www.migasreview.com

Badan Pengkajian dan Penerapan Teknologi. 2015. Outlook Energi Indonesia 2015. Jakarta: Pusat Teknologi Pengembangan Sumber Daya Energi (PTPSE)

Buchholz T, Luzadis VA, Volk TA. 2009. Sustainability Criteria for Bioenergy Systems: Results from an Expert Survey. Journal Of Cleaner Production, 17: S86S98.

Chavez RD, Johnson FX, Richard TL, Chanakya H. 2015. Biomass Resources, Energy Access and Poverty Reduction. SCOPE, 72: 779.

Chinigo D dan Kingiri A. 2013. Mainstreaming Gender in Bioenergy. PISCES Policy Brief, 7: 1-16

[EPA] Environmental Protection Agency. 2015. Overview of greenhouse gases [Internet]. [Diunduh 2017 Sept 21]. Tersedia https://www.epa.gov/ghgemissions/overviewgreenhouse-gases

[EPA] Environmental Protection Agency. 2016. Social cost of carbon [Internet]. [Diunduh 2018 Mei 10]. Tersedia pada:

https://www.epa.gov/sites/production/files/201212/documents/social_cost_of_carbon_fact_ sheet.pdf

Fauzi A, Anna Z. 2002. Evaluasi Status Keberlanjutan Pembangunan Perikanan: Aplikasi Pendekatan Rapfish. Jurnal Pesisir dan Lautan, 4(3): 43-55

[IEA] International Energy Agency. 2009. Bioenergy-a sustainable and reliable energy source [Internet]. [Diunduh 2017 Sep 21]. Tersedia pada:

http://www.ieabioenergy.com/wpcontent/uploads/ 2013/10/MAIN REPORT-Bioenergy-a-sustainableand-reliable-energy-source.-A-review-of-status-andprospects.pdf

Intergovernmental Panel on Climate Change. 2006. 2006 IPCC Guidelines for National Greenhouse Gas Inventories. Jepang: Institute for Global Environmental Strategies

Jumiati A, Dahlia. 2011. Penyelesaian Pencemaran Lingkungan Hidup Melalui Pendekatan Budaya Hukum dan Hubungan Kemitraan (Suatu Studi Kasus). Jurnal Wacana Hukum, 10 (11): 63-74

Kementerian Desa, Pembangunan Daerah Tertinggal dan Transmigrasi. 2016. Percepatan Pembangunan Desa. Jakarta: Kementerian Desa, Pembangunan Daerah Tertinggal dan Transmigrasi Republik Indonesia.

Kementerian Energi dan Sumber Daya Mineral. 2014. Buku Infromasi Bioenergi. Jakarta: Kementerian Energi dan Sumber Daya Mineral

Kementerian Energi dan Sumber Daya Mineral. 2016. Solusi Listrik Off-Grid Berbasis Energi Terbarukan di Indonesia. Jakarta: Kementerian Energi dan Sumber Daya Mineral

Peraturan Pemerintah Republik Indonesia. 2014. Peraturan Pemerintah Republik Indonesia No. 79 Tahun 2014 Tentang Kebijakan Energi Nasional (KEN)

Phonephachanh, K. 2012. Household Biogas Technology to Improve Rural Livelihoods in Laos. Journal of Developments in Sustainable Agriculture, 7: 158-163

Rahmani P, Hartono DM, Kusnoputranto H. 2013. Kajian Kelayakan Pemanfaatan Biogas Dari Pengolahan Air Limbah Untuk Memasak. Jurnal Ilmu Lingkungan, 11(2): $132-140$
Souza GM, Victoria R, Joly C, Verdade L. 2015. Bioenergy \& Sustainability: Bridging the Gaps. SCOPE, 72: 779

Sugiyono, A. 2016. Konsep Dana Ketahanan Energi. Prosiding Seminar Inovasi Teknologi untuk Mendukung Kemandirian Energi Nasional (2016 Des). Jakarta

United Nation. 2015. Sustainable Development Goals Fact Sheet. Amerika Serikat: United Nation.

Undang-Undang Republik Indonesia. 2014. Undang-Undang No. 06 Tahun 2014 Tentang Desa

Wamuyu, MS. 2014. Analysis of Biogas Technology for Household Energy, Sustainable Livelihoods and Climate Change Mitigation in Kiambu County, Kenya [disertasi]. Kenya: Kenyatta University

Young, FW. 1987. Multidimensional Scaling: History, Theory, and Applications. Amerika Serikat: Psychology Press

Zafar, S. 2018. Biomass as a Renewable Energy Resource [Internet]. [Diunduh 2018 Mei 14]. Tersedia pada: https://www.bioenergyconsult.com/biomassresources/ 